RUNNING HEAD: SOCIAL MEDIA USE AND ROMANTIC COMMITMENT

This is an Accepted Manuscript (post print version) of an article published by Wiley in Personal Relationships on 2/12/2019, available online:

https://onlinelibrary.wiley.com/doi/10.1111/pere.12299

\title{
Romantic Relationship Commitment and the Threat of Alternatives on Social Media
}

Orpha de Lenne ${ }^{1,2}$, Laurens Wittevronghel ${ }^{1}$, Laura Vandenbosch ${ }^{1}$, and Steven Eggermont ${ }^{1}$

Affiliations: ${ }^{1}$ School for Mass Communication Research, Faculty of Social Sciences, KU

Leuven, Leuven Belgium; ${ }^{2}$ Research Foundation Flanders (FWO-Vlaanderen)

Email addresses: orpha.delenne@kuleuven.be; laura.vandenbosch@kuleuven.be; steven.eggermont@kuleuven.be

Please cite as follows: de Lenne, O., Wittevronghel, L., Vandenbosch, L., \& Eggermont, S. (2018). Romantic relationship commitment and the threat of alternatives on social media. Personal Relationships. Advanced online publication. doi: 10.1111/pere.12299

Address correspondence to: Laura Vandenbosch, School for Mass Communication Research, KU Leuven, Parkstraat 45, B-3000 Leuven, Belgium, laura.vandenbosch@kuleuven.be, Tel: +3216323202. 


\begin{abstract}
Although previous findings suggest a link between adults' use of social networking sites (SNS) and relationship commitment, research has been lacking. The present study among 427 emerging and young adults (aged 18-32, 71.20\% female) indicated that exposure to alternative partners on SNS was indirectly related to relationship commitment through pursuing of alternative partners on SNS. The more frequently they were exposed to alternative partners on SNS, the more they engaged in pursuing these alternative partners, which negatively affected their relationship commitment. Furthermore, a positive relation between exposure and romantic comparison to alternative partners was found. Gender did not moderate these relations. The discussion focuses on the implications of the findings for relationship development.
\end{abstract}

Keywords: social networking sites, relationship commitment, alternative partners, social comparison theory, investment model, emerging and young adults 


\section{Romantic Relationship Commitment and the Threat of Alternatives on Social Media}

The majority of young adults are avid users of social networking sites (SNS) (e.g., 72\% in Lenhart, Purcell, Smith, \& Zickuhr, 2010). SNS are known to affect romantic relationship outcomes, such as relationship happiness (e.g., Utz \& Beukeboom, 2011), attachment (e.g., Fox \& Warber, 2014), jealousy (e.g., Muise, Christofides, \& Desmarais, 2009), and infidelity (e.g., Clayton, Nagurney, \& Smith, 2013). However, little research has considered relationship commitment and the threat of alternatives when studying the link between SNS use and romantic relationships.

The current cross-sectional study among emerging and young adults (aged 18-32) is one of the first studies to document the role of SNS and alternatives in the willingness to commit to a romantic partner. Our paper draws on both SNS literature (e.g., Frison \& Eggermont, 2016) and commitment models (e.g., Rusbult, 1980) and aims to gain a deeper understanding of the underlying mechanisms explaining the relation between exposure to alternative partners on SNS and commitment by examining three factors: (1) pursuing of alternative partners, (2) romantic comparison processes, and (3) gender.

\section{Alternative Partners, Romantic Comparison, and Relationship Commitment}

Relationship commitment can be defined as a partners' willingness to establish and invest in a long-term romantic relationship (Surra \& Hughes, 1997). A well-established theoretical framework to understand and describe relationship commitment is Rusbult's Investment Model. This model proposes three determinants shape relationship commitment: satisfaction with the relationship, dependence on investments in the relationship, and the quality of alternatives (Rusbult, 1980). Empirical research has consistently found that each of these three factors affect relationship commitment within various populations and contexts (Le \& Agnew, 2003). Recently, the quality of alternatives has received additional attention within the literature given the changed digital media landscape that now allows individuals to meet new 


\section{SOCIAL MEDIA USE AND ROMANTIC COMMITMENT}

people at an unprecedented rate (West, 2013). Within commitment literature, alternatives are defined as the presence of other options than the relationship with the current partner (Rusbult, 1980). Such alternatives are not necessarily other possible romantic partners or relationships. Rusbult (1980) explained that remaining single may be preferred above one's current relationship and may thus also be perceived as a possible alternative. However, alternatives are typically interpreted and studied within current research as other romantic suitors (e.g., Miller, 1997). The Investment Model explains that relationship commitment decreases when a large pool of other attractive partners are available (Rusbult, 1980). More precisely, when many other suitors are available, a current romantic partner is perceived more easily as "replaceable" as many others can fulfill one's relationship needs and some alternatives may even be perceived as superior. Accordingly, one's relationship commitment decreases (Rusbult, 1980). Overall, relationship commitment will be influenced by the amount of attractive alternatives and thus the extent to which preferred relationship outcomes can be satisfied in other possible relationships.

Building on Interdependence Theory (Thibaut \& Kelley, 1959), Rusbult's Investment Model further assumes that individuals evaluate the quality of these alternatives by using social comparison (Rusbult, 1980). Social comparison processes occur when individuals actively apply information about others to make comparative judgments about their own situation (Festinger, 1954). Applied to the context of romantic relationships, Interdependence Theory (Thibaut \& Kelley, 1959) explains that individuals assess the rewards and costs or satisfaction about their current relationship by using comparison levels. Comparison levels are individuals' expectations about what the ideal relationship should look like. Such comparison levels are based on previous relationship experiences or observing other people's relationships (Thibaut \& Kelley, 1959). Individuals thus determine their relationship satisfaction and weigh the benefits and costs of the relationship by comparing current relationship outcomes to their 


\section{SOCIAL MEDIA USE AND ROMANTIC COMMITMENT}

expected relationship outcomes. The Investment Model builds on this idea of comparison levels when explaining how alternatives affect relationship commitment (West, 2013). The model explains that individuals use comparison levels to assess the quality of alternatives (Rusbult, 1980; West, 2013). This means that individuals assess the benefits and costs of staying in their relationship when considering the possibility of an alternative relationship (West, 2013), which we will define throughout this study as romantic comparison.

\section{Commitment Processes on SNS}

Although the power of Rusbult's Investment Model has been extensively demonstrated (Le \& Agnew, 2003; Rusbult, 1980), research studying the assumptions of the model while taking into account the current social media environment is rather scarce, but suggested to be necessary: Literature has indicated that SNS play an important role in the development and maintenance of romantic relationships (Elphinston \& Noller, 2011). More specifically, SNS may generate the impression that there are many suitable alternatives and also facilitate romantic comparison processes to assess the quality of such alternatives (West, 2013).

The assessment of the quality of alternatives is enhanced by the features of SNS, for instance, by its continuous updates of how interesting others' activities are (West, 2013). These activities, but also others' presented appearance on SNS may generate the impression that there are many suitable alternatives because users typically present idealized content. SNS users' online self-presentation is often biased (Mendelson \& Papacharissi, 2010), as users carefully select the parts of their personal and social lives that they share online (Ellison, Heino, \& Gibbs, 2006). This selection process helps to present a highly desired and flattering image of the user (Mendelson \& Papacharissi, 2010), for instance, by only posting physically attractive pictures (Siibak, 2009), and deleting or "untagging'" pictures in which the user thinks he or she deviates from contemporary appearance standards (McLaughlin \& Vitak, 2012). Similarly, users are eager to share personal and professional achievements (e.g., graduation) (Baek, Holton, Harp, 


\section{SOCIAL MEDIA USE AND ROMANTIC COMMITMENT}

\& Yaschur, 2011; Mendelson \& Papacharissi, 2010) and to display pictures with others and friend lists, so that they can emphasize their popularity status (Siibak, 2009; Zhao, Grasmuck, \& Martin, 2008). As such, SNS are filled with so-called "ideal" rather than "actual" selfportrayals. People who thus frequently use SNS can be expected to be regularly exposed to ideal self-presentations of other SNS profile owners. Indeed, prior research has indicated that more frequent use of SNS entails more exposure to the profiles of and information shared by other users (Joinson, 2008). Such exposure may be paired with impressions that there are many suitable and attractive potential partners, given the overly positive self-presentations of SNS users (Chua \& Chang, 2016). Following the assumptions of the Investment Model (Rusbult, 1980), such impressions are likely to be a threat for partners' relationship commitment.

This possible negative relation between exposure to alternative partners on SNS and relationship commitment may be further explained by online pursuing of alternative partners, a practice that is quite common according to SNS research (e.g., Abbasi \& Alghamdi, 2018). SNS not only allow individuals to monitor attractive alternatives but also facilitate contact with them as users can like each other's posts or chat within the online platform (Abbasi \& Alghamdi, 2018). The affordance of SNS to easily communicate with others may thus enhance the pursuing of alternative partners after being exposed to them in SNS. Research suggests that at least a part of those in a relationship is involved in such pursuing behavior. Results indeed found that SNS users seek online contact with individuals with whom they want to get romantically involved (Drouin, Miller, \& Dibble, 2014) by commenting on their pictures or sending private messages or friend requests (Abbasi \& Alghamdi, 2018). Research also found that SNS facilitate infidelity behaviors including online flirting or cybersex (Abbasi \& Alghamdi, 2018) and even engaging in sexual affairs (Abbasi \& Alghamdi, 2017). Such pursuing behaviors are known to be damaging for one's relationship commitment (Frisby \& Booth-Butterfield, 2012) and also increase negative relationship outcomes such as jealousy, 


\section{SOCIAL MEDIA USE AND ROMANTIC COMMITMENT}

suspicion, and conflict (Clayton et al., 2013; Muise et al., 2009). Overall, the literature hints at the idea that individuals are not only exposed to alternative partners on SNS, but also that such exposure on SNS facilitates the pursuing of attractive alternatives. Pursuing behavior, in turn, has been shown to negatively affect relationship commitment. As such we hypothesized:

H1: Exposure to alternative partners on SNS is positively related to pursuing of alternative partners on SNS. In turn, this pursuing behavior is negatively related to relationship commitment.

Comparison processes are highly common when using SNS (McAndrew \& Jeong, 2012). Online comparison processes are mostly upward, meaning that one's own situation is compared to a more ideal situation. As SNS seem to be filled with attractive individuals who have a pleasant personality and attractive lifestyle, alternative partners on SNS may be perceived as rather ideal and their traits may be compared in an upward fashion to the traits of one's own partner (Steers, Wickham, \& Acitelli, 2014). The outcome of this romantic comparison may influence general relational attitudes (Stalder, 2012) and perceptions about their current partner (Surra \& Hughes, 1997) in a negative direction. Such romantic comparison processes can lead to the impression that the current relationship brings more costs than benefits. Individuals may consequently think that they are settling for less than is possible (Buunk, Oldersma, \& de Dreu, 2001) which may lower one's relationship commitment. It is thus likely that both exposure to alternative partners on SNS and pursuing of alternative partners on SNS generate romantic comparison processes that are in turn again negatively related to relationship commitment. Therefore, we hypothesized the following:

$\mathrm{H} 2$ : Exposure to alternative partners on SNS is positively related to romantic comparison to alternative partners on SNS. In turn, this romantic comparison is negatively related to relationship commitment. 


\section{SOCIAL MEDIA USE AND ROMANTIC COMMITMENT}

H3: Pursuing of alternative partners on SNS is positively related to romantic comparison to alternative partners on SNS. In turn, this romantic comparison is negatively related to relationship commitment.

\section{Moderating Role of Gender}

Gender may moderate the hypothesized relations. Previous research has shown that men report higher levels of online monitoring of alternatives and lower levels of relationship commitment than women (West, 2013). This research also showed that online monitoring of alternatives more strongly predicted men's relational commitment as compared to women's commitment (West, 2013). As such, the negative relations between exposure to alternative partners on SNS and relationship commitment through pursuing and romantic comparison may be stronger for men than for women. Therefore, we hypothesized:

H4: The relations between exposure to alternative partners on SNS, pursuing of alternative partners on SNS, romantic comparison to alternative partners on SNS and relationship commitment are stronger for men than for women.

\section{Method}

\section{Sample and Procedure}

After receiving ethical approval from the institutional review board of the KU Leuven, a sample of emerging and young adults was collected in March-April 2017 through a call on social media and email distributed among the network of a group of college students. Before starting the online questionnaire, each participant was presented with an informed consent form, and informed on practicalities and the incentive (chance to win a coupon). As building a committed relationship is a primary goal in early adulthood (Rappleyea, Taylor, \& Fang, 2014), this study focused on emerging and young adults. Participants not belonging to the targeted age group (i.e., younger than 18 or older than 35 ) were therefore deleted from the sample. The questionnaire also included an attention check asking respondents to answer the answering 


\section{SOCIAL MEDIA USE AND ROMANTIC COMMITMENT}

option "completely agree" to assess whether they were attentive. Respondents who failed to answer this check correctly (i.e., did not answer the question or answered a different answer than asked) were deleted as we are not sure to which extent their responses are trustworthy. As this study focuses on individuals in a relationship, participants who were single or did not fill in their relationship status were not taken into account in the analyses. The remaining analytical sample consisted of 427 participants $(71.20 \%$ women, $M$ age $=23.16, S D=3.10)$. The majority $(51.5 \%)$ were college students, $35.4 \%$ was working, $10.3 \%$ combined work and study, and $2.8 \%$ was neither studying nor working.

\section{Measures}

Moderator and control variables. Participants reported their gender $(1=$ male, $2=$ female $)$ and age. SNS frequency was measured by asking respondents "How frequently do you visit social networking sites such as Facebook." Answer options included 1 (= never), 2 (= less than once a month), 3 (= one to three times a month), 4 (= once every two weeks), 5 (= several times a week), 6 (=daily), 7 (= several times a day), and 8 (= all day long).

\section{Exposure to alternative partners on SNS and pursuing of alternative partners on SNS.}

An adapted version of the Online Monitoring of Alternatives Scale (West, 2013) was used. The scale contained six items : "I am distracted by all the people I find attractive on social media", "Because of social media, I am aware that there are plenty of fish in the sea", "I notice a lot of pretty, attractive people on social media", "I flirt with numerous people who I meet on social media (without telling them I have a partner)", "I am romantically interested in people who I meet through social media", and "On social media (and without my partner knowing), I communicate with people who I would want to date someday." Items were rated on a 5-point Likert scale from 1 (= never) to 5 (= always). Principal components analysis (PCA) yielded two factors (factor 1 : eigenvalue $=2.67$, explained variance $=44.46 \%$; factor 2 : eigenvalue $=$ 1.06, explained variance $=17.63 \%$ ). Although this scale has been validated in previous 


\section{SOCIAL MEDIA USE AND ROMANTIC COMMITMENT}

literature, research has highlighted the importance of distinguishing between passive and active use of SNS (Frison \& Eggermont, 2016) and therefore we decided to take into account the results of the PCA and to separate the items. The first three items clustered on factor 1 and represented a more passive way of monitoring alternatives, which we defined as exposure to alternatives on SNS. This scale was found to be reliable (Cronbach's alpha $\alpha=.71$ ) and the items were taken together into a new variable by averaging the item scores. The fourth and sixth item clustered on factor 2 and represented a more active way of monitoring alternatives, which we defined as pursuing of alternative partners on SNS. The fourth item cross loaded on both factors and was therefore not taken into account in further analyses. The fourth and sixth item were taken together into a new variable by averaging the item scores. This scale was found to be reliable $(r=.52, p<.001)$.

Romantic comparison to alternative partners on SNS. The adapted Online Social Comparison Scale (West, 2013) was used. The scale had two items: "When I see pictures of others on social media, I compare my partner to them" and "If I talk to others on social media with whom I could date, I compare my partner with them.” Items were rated on a 7-point Likert scale ranging from 1 (= completely disagree) to 7 (= completely agree). PCA ensured the onefactor dimension of the scale and a new variable was created by averaging the item scores (eigenvalue $=1.69$, explained variance $=84.50 \%, r=.69, p<.001)$.

Relationship commitment. The Commitment subscale of the Investment Model Scale (Rusbult, Martz, \& Agnew, 1998) was used. This scale contains seven items, such as"I am committed to maintaining my relationship with my partner" and "I want our relationship to last for a very long time." Items were rated on a 7-point Likert scale from 1 (=totally disagree) to 7 (= totally agree). PCA ensured the one-factor dimension of the scale and a new variable was created by averaging the item scores (eigenvalue $=4.77$, explained variance $=68.13 \%, \alpha=$ $.92)$. 


\section{SOCIAL MEDIA USE AND ROMANTIC COMMITMENT}

\section{Analysis}

The main model (H1-H3, see Figure 1) was tested using structural equation modelling with Mplus. All constructs (except for the control variables) were entered as latent variables and predicted by their respective manifest items. In line with prior media research (e.g., Frison \& Eggermont, 2016; Trekels \& Eggermont, 2018), gender, age, and SNS frequency were entered as control variables by modelling predictive pathways to the mediating and dependent variables and covariances with the independent variable. Indirect effects were further calculated to test the mediating role of pursuing alternative partners and romantic comparison to alternative partners on SNS. A direct relation between exposure to alternative partners on SNS and relationship commitment was also included because it is possible that pursuing alternative partners and romantic comparison do not fully capture the variance of commitment. To test the moderating role of gender $(\mathrm{H} 4)$, a $\chi^{2}$-difference test comparing an unconstrained model (multigroup model with no equality constraints) to a constrained model (multigroup model with equality constraints) was calculated. Difference parameters were further added to determine which pathways differed between men and women.

Because this is a cross-sectional study, we also tested two alternative models to rule out other directional paths. The first alternative model (see Figure 2) changed the direction of the relation between pursuing alternative partners and romantic comparison. The second alternative model (see Figure 3) tested the possibility of relationship commitment as an independent variable and exposure, pursuing, and romantic comparison of alternative partners on SNS as dependent variables.

To validate the significance of the examined pathways, bootstrapping (95\% bias-corrected bootstrapped confidence intervals [bc $95 \%$ bt CI]; 1000 bootstrapped samples) were used while full information maximum likelihood in Mplus was used to address missing data (Muthén \& Muthén, 2017). Confidence intervals and $\mathrm{p}$ values of standardized model results were reported. 


\section{Results}

First, we calculated descriptive statistics and zero-order correlations (see Table 1). Respondents indicated to be occasionally exposed to alternative partners on SNS. They also reported to rarely pursue such alternative partners. Furthermore, they indicated to infrequently compare their partner to alternative partners on SNS. The average reported relationship commitment was rather high.

\section{[INSERT TABLE 1]}

\section{Main Model}

The main model showed a good fit with the data (see Figure 1): Chi-square $\chi^{2}(101)=284.29$, $p<.001, A I C=16852.57$, RMSEA $=.07(90 \%$ CI: $.06 / .07), C F I=.94, T L I=.92, S R M R=$ .04. The model showed that exposure to alternative partners on SNS was positively related to pursuing of alternative partners, which was, in turn negatively related to relationship commitment. H1 was thus confirmed. Furthermore, the results indicated that exposure was positively related to romantic comparison. However, no significant relation was found between romantic comparison and relationship commitment, thus partly supporting $\mathrm{H} 2$. Pursuing of alternative partners was also not related to romantic comparison. H3 was thus rejected.

Furthermore, the overall indirect relation between exposure to alternative partners on SNS and relationship commitment through pursuing of alternative partners on SNS was found to be significantly negative, $\beta=-.21, B=-.27, S E=.10, p<.01$ (bc 95\% bt CI: $-.38 /-.10$ ). No direct relation was found between exposure of alternative partners on SNS and relationship commitment, indicating full mediation of pursuing of alternative partners.

\section{[INSERT FIGURE 1]}

Finally, we investigated whether the model results described above were the same for men and women. The $\chi^{2}$-difference test was significant $\left(\Delta \chi^{2}(6)=20.64, p<.01\right)$. The unconstrained model $\left(\chi^{2}(202)=424.35, p<.001, R M S E A=.07(90 \%\right.$ CI: $.06 / .08), C F I=.92, T L I=.91$, 
SOCIAL MEDIA USE AND ROMANTIC COMMITMENT

$S R M R=.08)$ did significantly differ from the constrained model $\left(\chi^{2}(208)=444.99, p<.001\right.$, RMSEA $=.07(90 \%$ CI: .06/.08), CFI $=.92, T L I=.91, S R M R=.09)$. However, the results of the path-by-path analysis showed that none of the difference parameters were significant. Although the $\chi^{2}$-difference test was significant, thus initially indicating differences between men and women, the results of the path-by-path analysis may indicate that these differences are negligible. Cheung and Rensvold (2002) indicate that when the difference of the CFI value is smaller than or equal to -.01, the null hypothesis of invariance should not be rejected. Since the CFI difference $(\Delta \mathrm{CFI}=-.005)$ between the unconstrained model $(\mathrm{CFI}=.924)$ and the constrained model $(\mathrm{CFI}=.919)$ was indeed smaller than -.01 , we can assume that there were no differences between men and women and thus reject $\mathrm{H} 4$.

\section{Alternative Models}

The first alternative model showed a good fit with the data (see Figure 2$): \chi^{2}(101)=284.29$, $p<.001, R M S E A=.07$ (90\% CI: .06/.07), CFI $=.94, T L I=.92, S R M R=.04, A I C=16852.57$. The reversed relation between pursuing of alternative partners on SNS and romantic comparison to alternative partners on SNS was not significant. Furthermore, the same relations as in the main model were found to be significant.

The second alternative model also showed a good fit with the data (see Figure 3$): \chi^{2}(101)=$ 284.29, $p<.001, R M S E A=.07$ (90\% CI: .06 / .07), CFI $=.94, T L I=.92$, SRMR $=.04$, AIC $=$ 16852.57. A significant negative relation was found between relationship commitment, exposure to alternative partners, pursuing of alternative partners, and romantic comparison to alternative partners on SNS.

The AIC of these alternative models did not differ from the AIC of the main model, meaning that the alternative models are not necessarily better compared to the original model.

[INSERT FIGURE 2 AND 3]

\section{Discussion}




\section{SOCIAL MEDIA USE AND ROMANTIC COMMITMENT}

The current cross-sectional study among emerging and young adults provides new insights into the role of SNS in romantic relationships. Our study shows that the assumptions of Rusbult's Investment Model not only hold in the offline world, but are also an important theoretical framework when investigating relationship commitment in the social media environment. First, the results indicated an indirect negative relation between exposure to alternative partners on SNS and commitment via pursuing of alternative partners on SNS. More frequent exposure to alternative partners thus predicted more pursuing of alternative partners and this pursuing behavior was, in turn, negatively related to commitment (H1). These results align with the principles of Rusbult's model (1980) which claims that commitment to a partner decreases when the number of perceived available alternative partner increases.

Second, our findings indicated a positive relation between exposure to alternative partners on SNS and romantic comparison to alternative partners on SNS. However, no relation was found between romantic comparison and commitment and $\mathrm{H} 2$ was thus only partly supported. The more frequently young adults were exposed to alternative partners on SNS, the more they indicated to engage in romantic comparison processes between one's own current partner and potential alternative partners on SNS. This finding supports researchers' observation that the online world is an important context for the manifestation of comparison processes (Haferkamp \& Krämer, 2011) and is in line with Rusbult's Investment Model (1980) indicating individuals use comparison levels to assess the quality of their current relationship. Our results further indicate that engaging in romantic comparison processes is not necessarily linked to lower relationship commitment. This finding is in contrast with existing research claiming that comparing one's current partner to the ideal partners may be harmful for one's relationship commitment (Stalder, 2012). Pursuing of alternative partners thus seemed to be a more important explanatory factor in the relationship between exposure to alternative partners on SNS and relationship commitment than romantic comparison. It is possible that romantic 


\section{SOCIAL MEDIA USE AND ROMANTIC COMMITMENT}

comparison is a rather passive SNS activity that individuals can perform anonymously and from a distance without having to actually engage with the alternative partner. As such, it may be possible that romantic comparison is less invasive and harmful for relationship commitment compared to pursuing of alternative partners, which is more of an active SNS behavior. Future research should further investigate this reasoning though.

Third, we did not find a significant relationship between the pursuing of alternative partners on SNS and romantic comparison to alternative partners on SNS. H3 was thus rejected. We reasoned that as pursuing is a step further than merely exposure, and thus actually allows individuals to engage with the alternative partner, this would also give them more information about the alternative partner and facilitates romantic comparison processes. Because it is also possible that individuals first compare an alternative partner to their current partner before actually pursuing this alternative partner, we tested an alternative model in which romantic comparison was entered to predict pursuing of alternative partners on SNS. Again, no significant relation was found between romantic comparison and pursuing.

Finally, we did not find any differences between men and women (H4). This is in contrast with existing literature claiming that the relations between online monitoring of alternatives and relationship commitment are stronger for men than for women (West, 2013). Other more specific moderators such as relationship factors (e.g., attachment bounds; Joel, Macdonald, \& Shimotomai, 2011) or personality traits (e.g., sensation seeking; Shafiee \& Etemadi, 2018) may potentially be more successful in unravelling the conditions under which exposure to alternative partners on SNS stimulates or decreases commitment.

Our findings have several limitations. First, the cross-sectional design clearly does not allow causal implications. This limitation was further illustrated by the first alternative model, in which commitment was entered as independent variable and exposure, pursuing, and commitment as dependent variables. The model fit of the alternative model was the same as 


\section{SOCIAL MEDIA USE AND ROMANTIC COMMITMENT}

the model fit from the initial hypothesized model, thus indicating that relationship commitment may also determine to which extent individuals pay attention to alternatives on SNS. This is in line with literature on defence mechanisms claiming that people who are in a happy, committed relationship develop certain defence mechanisms in which they become inattentive to alternatives (Miller, 1997). Future research should further investigate possible bidirectional relations between exposure/pursuing/comparison and relationship commitment. Second, the research was conducted in Flanders, Belgium. This European, Western cultural context may hinder the generalization of the results; research with an intercultural comparison perspective seems warranted. Third, the test-retest reliability and validity of the newly developed measures need to be further explored. Especially the reliability of pursuing of alternative partners on SNS was found to be rather low. Fourth, the study uses self-reported data which could affect the accuracy of social media frequency and activities that were studied in this paper.

\section{Conclusion}

In conclusion, this study indicates that pursuing of alternative partners is an important explanatory factor in the relations between exposure to alternative partners on SNS and relationship commitment. This paper thus illustrates the importance of distinguishing between passive SNS and active SNS behaviors when studying the relations between SNS use and relationship commitment. 


\section{References}

Abbasi, I. S., \& Alghamdi, N. G. (2017). When flirting turns into infidelity: The Facebook dilemma. The American Journal of Family Therapy, 45, 1-14. doi:10.1080/01926187.2016.1277804

Abbasi, I. S., \& Alghamdi, N. G. (2018). The pursuit of romantic alternatives online: Social media friends as potential alternatives. Journal of Sex \& Marital Therapy, 44, 16-28. doi:10.1080/0092623X.2017.1308450

Baek, K., Holton, A., Harp, D., \& Yaschur, C. (2011). The links that bind: Uncovering novel motivations for linking on Facebook. Computers in Human Behavior, 27, 2243-2248. doi:10.1016/j.chb.2011.07.003

Buunk, B. P., Oldersma, F. L., \& de Dreu, C. K. W. (2001). Enhancing satisfaction through downward comparison: The role of relational discontent and individual differences in social comparison orientation. Journal of Experimental Social Psychology, 37, 452-467. doi:10.1006/jesp.2000.1465

Cheung, G.W., \& Rensvold, R.B. (2002). Evaluating goodness-of-fit indexes for testing measurement invariance. Structural Equation Modeling: A Multidisciplinary Journal, 9, 233-255. doi:10.1207/S15328007SEM0902_5

Chua, T. H. H., \& Chang, L. (2016). Follow me and like my beautiful selfies: Singapore teenage girls' engagement in self-presentation and peer comparison on social media. Computers in Human Behavior, 55, 190-197. doi:10.1016/j.chb.2015.09.011

Clayton, R. B., Nagurney, A., \& Smith, J. R. (2013). Cheating, breakup, and divorce: Is Facebook use to blame? Cyberpsychology, Behavior, and Social Networking, 16, 717-720. doi:10.1089/cyber.2012.0424 


\section{SOCIAL MEDIA USE AND ROMANTIC COMMITMENT}

Drouin, M., Miller, D. A., \& Dibble, J. L. (2014). Ignore your partners' current Facebook friends; beware the ones they add! Computers in Human Behavior, 35, 483-488. doi:10.1016/j.chb.2014.02.032

Ellison, N., Heino, R., \& Gibbs, J. (2006). Managing impressions online: Self-presentation processes in the online dating environment. Journal of Computer-Mediated Communication, 11, 415-441. doi:10.1111/j.1083-6101.2006.00020.x

Elphinston, R. A., \& Noller, P. (2011). Time to face it! Facebook intrusion and the implications for romantic jealousy and relationship satisfaction. Cyberpsychology, Behavior, and Social Networking, 14, 631-635. doi:10.1089/cyber.2010.0318

Festinger, L. (1954). A theory of social comparison processes. Human Relations, 7, 117-140. doi:10.1177/001872675400700202

Fox, J., \& Warber, K. M. (2014). Social networking sites in romantic relationships: Attachment, uncertainty, and partner surveillance on Facebook. Cyberpsychology, Behavior, and Social Networking, 17, 3-7. doi:10.1089/cyber.2012.0667

Frisby, B. N., \& Booth-Butterfield, M. (2012). The "how" and "why" of flirtatious communication between marital partners. Communication Quarterly, 60, 465-480. doi:10.1080/01463373.2012.704568

Frison, E., \& Eggermont, S. (2016). How Facebook makes teens (un)happy: Understanding the relationships between Facebook use and adolescents' well-being. (KU Leuven. Nieuwe reeks van doctoraten in de sociale wetenschappen en in de sociale en culturele antropologie 302). Leuven: KU Leuven. Faculteit Sociale wetenschappen.

Haferkamp, N., \& Krämer, N. C. (2011). Social comparison 2.0: Examining the effects of online profiles on social-networking sites. Cyberpsychology, Behavior, and Social Networking, 14, 309-314. doi:10.1089/cyber.2010.0120 
SOCIAL MEDIA USE AND ROMANTIC COMMITMENT

Joinson, A. N. (2008). Looking at, looking up or keeping up with people?: Motives and use of Facebook. Presented at the SIGCHI Conference on Human Factors in Computing Systems, Florence, Italy, New York: ACM Press. doi:10.1145/1357054.1357213

Joel, S., MacDonald, G., \& Shimotomai, A. (2011). Conflicting pressures on romantic relationship commitment for anxiously attached individuals: Commitment and anxious attachment. Journal of Personality, 79, 51-74. doi:10.1111/j.1467-6494.2010.00680.x

Le, B., \& Agnew, C. R. (2003). Commitment and its theorized determinants: A meta-analysis of the Investment Model. Personal Relationships, 10, 37-57. doi:10.1111/14756811.00035

Lenhart, A., Purcell, K., Smith, A., \& Zickuhr, K. (2010). Social media \& mobile internet use among teens and young adults. Millennials. Pew Internet \& American Life Project. Retrieved from http://www.pewinternet.org/files/oldmedia/Files/Reports/2010/PIP_Social_Media_and_Young_Adults_Report_Final_with_top lines.pdf

McAndrew, F. T., \& Jeong, H. S. (2012). Who does what on Facebook? Age, sex, and relationship status as predictors of Facebook use. Computers in Human Behavior, 28, 2359-2365. doi:10.1016/j.chb.2012.07.007

McLaughlin, C., \& Vitak, J. (2012). Norm evolution and violation on Facebook. New Media \& Society, 14, 299-315. doi:10.1177/1461444811412712

Mendelson, A. L., \& Papacharissi, Z. (2010). Look at us: Collective narcissism in college student Facebook photo galleries In Z. Papacharissi (Ed.), A Networked Self: Identity, Community and Culture on Social Network Sites (251-273). New York, NY: Routledge.

Miller, R. S. (1997). Inattentive and contented: Relationship commitment and attention to alternatives. Journal of Personality and Social Psychology, 73, 758-766. doi:10.1037/0022-3514.73.4.758 
SOCIAL MEDIA USE AND ROMANTIC COMMITMENT

Muise, A., Christofides, E., \& Desmarais, S. (2009). More information than you ever wanted: Does Facebook bring out the green-eyed monster of jealousy? CyberPsychology \& Behavior, 12, 441-444. doi:10.1089/cpb.2008.0263

Muthén, L. K., \& Muthén, B. O. (2017). Mplus User’s Guide (Eight Edition). Los Angeles, CA: Muthén \& Muthén.

Rappleyea, D. L., Taylor, A. C., \& Fang, X. (2014). Gender differences and communication technology use among emerging adults in the initiation of dating relationships. Marriage \& Family Review, 50, 269-284. doi:10.1080/01494929.2013.879552

Rusbult, C. E. (1980). Commitment and satisfaction in romantic associations: A test of the investment model. Journal of Experimental Social Psychology, 16, 172-186. doi:10.1016/0022-1031(80)90007-4

Rusbult, C. E., Martz, J. M., \& Agnew, C. R. (1998). The investment model scale: Measuring commitment level, satisfaction level, quality of alternatives, and investment size. Personal Relationships, 5, 357-387. doi:10.1111/j.1475-6811.1998.tb00177.x

Shafiee, Z., \& Etemadi, O. (2018). Predicting desire to betrayal based on romance jealous and sensation seeking in married women. Journal of Fundamentals of Mental Health, 20, 121130. doi:10.22038/jfmh.2018.10462

Siibak, A. (2009). Constructing the self through the photo selection-visual impression management on social networking websites. Cyberpsychology: Journal of Psychosocial Research on Cyberspace, 3(1).

Stalder, D. R. (2012). The role of dissonance, social comparison, and marital status in thinking about divorce. Journal of Social and Personal Relationships, 29, 302-323. doi:10.1177/0265407511431179 


\section{SOCIAL MEDIA USE AND ROMANTIC COMMITMENT}

Steers, M.-L. N., Wickham, R. E., \& Acitelli, L. K. (2014). Seeing everyone else's highlight reels: how facebook usage is linked to depressive symptoms. Journal of Social and Clinical Psychology, 33, 701-731. doi:10.1521/jscp.2014.33.8.701

Surra, C. A., \& Hughes, D. K. (1997). Commitment processes in accounts of the development of premarital relationships. Journal of Marriage and the Family, 59, 5. doi:10.2307/353658

Thibaut, J. W., \& Kelley, H. H. (1959). The Social Psychology of Groups. New York, NY: Wiley

Trekels, J., \& Eggermont, S. (2018). "I can/should look like a media figure”: The association between direct and indirect media exposure and teens' sexualizing appearance behaviors. The Journal of Sex Research, 55, 320-333. doi:10.1080/00224499.2017.1387754

Utz, S., \& Beukeboom, C. J. (2011). The role of social network sites in romantic relationships: Effects on jealousy and relationship happiness. Journal of ComputerMediated Communication, 16, 511-527. doi:10.1111/j.1083-6101.2011.01552.x

West, A. R. (2013). Relationship commitment and monitoring alternatives using Facebook in unmarried romantic relationships (Doctoral dissertation). Retrieved from https://repositories.lib.utexas.edu/bitstream/handle/2152/21578/WESTDISSERTATION-2013.pdf?sequence=1\&isAllowed=y

Zhao, S., Grasmuck, S., \& Martin, J. (2008). Identity construction on Facebook: Digital empowerment in anchored relationships. Computers in Human Behavior, 24, 1816doi:10.1016/j.chb.2008.02.012 
SOCIAL MEDIA USE AND ROMANTIC COMMITMENT

Table 1.

Descriptive Statistics and Zero-Order Correlations

Descriptive statistics

Zero-order correlations

\begin{tabular}{|c|c|c|c|c|c|c|c|c|c|c|c|c|c|}
\hline & \multicolumn{4}{|c|}{$\begin{array}{l}\text { General } \\
(N=427)\end{array}$} & \multicolumn{2}{|c|}{$\begin{array}{c}\text { Men } \\
(N=123)\end{array}$} & \multicolumn{2}{|c|}{$\begin{array}{l}\text { Women } \\
(N=304)\end{array}$} & 1 & 2 & 3 & 4 & 5 \\
\hline 1. SNS Frequency & 6.90 & .92 & 1 & 8 & 6.73 & 1.12 & 6.97 & .82 & --- & & & & \\
\hline $\begin{array}{l}\text { 3. Pursuing of } \\
\text { alternative partners }\end{array}$ & 1.22 & .49 & 1 & 5 & 1.41 & .66 & 1.15 & .37 & .01 & $.38^{* * * *}$ & --- & & \\
\hline 5. Commitment & 6.34 & .84 & 1 & 7 & 6.02 & 1.03 & 6.47 & .70 & .06 & $-.21^{* * *}$ & $-.38^{* * *}$ & $-.27^{* * *}$ & --- \\
\hline
\end{tabular}

Note. $* p<.05, * * p<.01$

Note. A MANOVA analysis showed the key variables differed significantly between men and women, $V=.13, F(5,391)=11.66, p<.001$. An univariate ANOVA revealed significant gender differences on exposure to alternative partners, $F(1,396)=26.92, p<.001)$, pursuing of alternative partners, $F(1,396)=24.37, p<.001$, romantic comparison, $F(1,396)=6.01, p<.05$,

commitment, $F(1,425)=27.72, p<.001$, and frequency of SNS usage, $F(1,397)=5.60, p<.05$. Men scored higher on exposure to alternative partners, pursuing of alternative partners, and

romantic comparison, and lower on commitment and SNS frequency. 


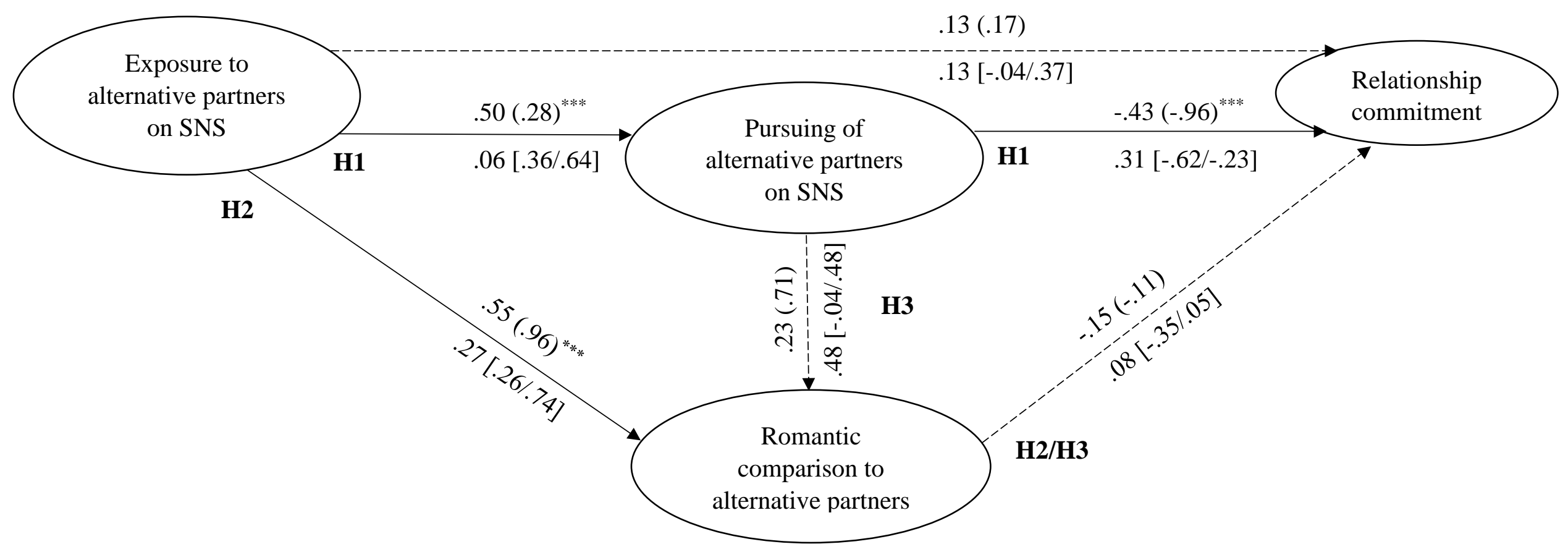

Figure 1. Structural equation model of the main hypothesized relations between exposure to alternative partners on SNS, pursuing of alternative partners on SNS, romantic comparison to alternative partners on SNS, and relationship commitment $(\mathrm{N}=427)$.

$\chi^{2}(101)=284.29, p<.001, A I C=16852.57, R M S E A=.07(90 \%$ CI: $.06 / .07), C F I=.94, T L I=.92, S R M R=.04$.

Note. These results are controlled for age, gender, and SNS frequency.

Above the arrow: First value reflect standardized coefficient (beta), value within brackets reflects unstandardized coefficients (b-value).

Below the arrow: First value reflects standard errors, values within squared brackets reflect $95 \%$ confidence intervals.

$* p<.05, * * p<.01, * * * p<.001$; dashed lines are non-significant paths. 


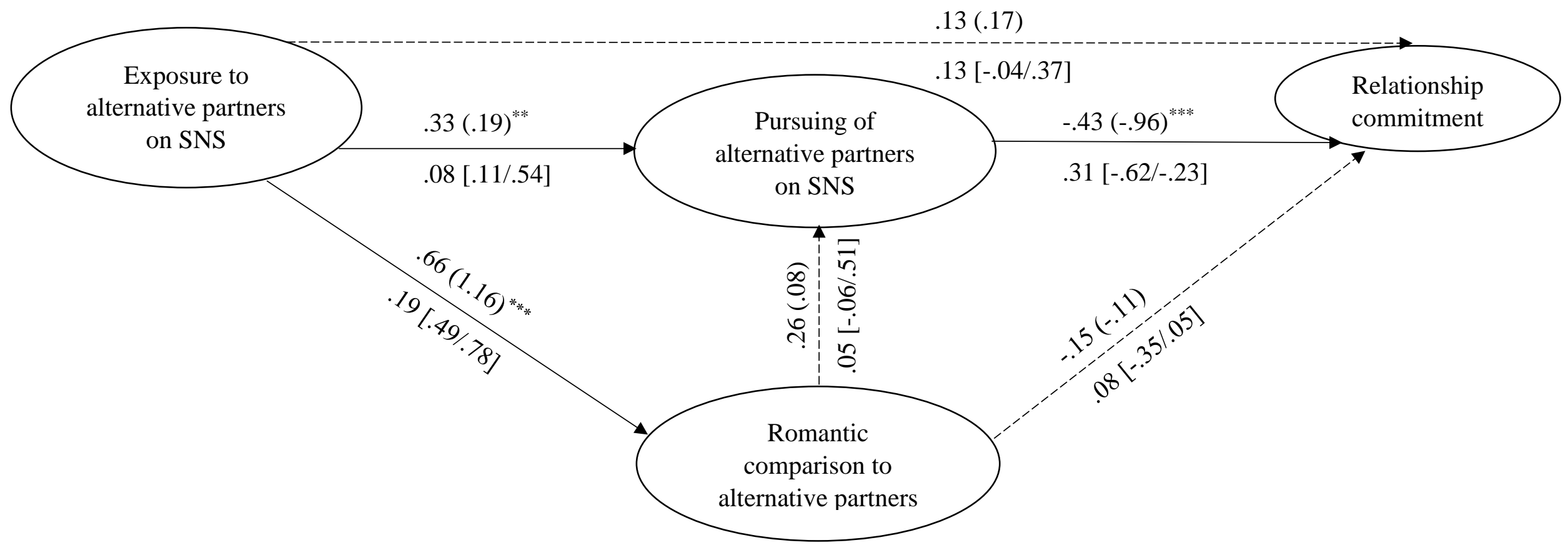

Figure 2. Structural equation model of alternative model 1.

$\chi^{2}(101)=284.29, p<.001, A I C=16852.57, R M S E A=.07(90 \%$ CI: .06 / .07), CFI $=.94, T L I=.92, S R M R=.04$.

Note. These results are controlled for age, gender, and SNS frequency.

Above the arrow: First value reflect standardized coefficient (beta), value within brackets reflects unstandardized coefficients (b-value).

Below the arrow: First value reflects standard errors, values within squared brackets reflect $95 \%$ confidence intervals.

$* p<.05, * * p<.01, * * * p<.001 ;$ dashed lines are non-significant paths. 


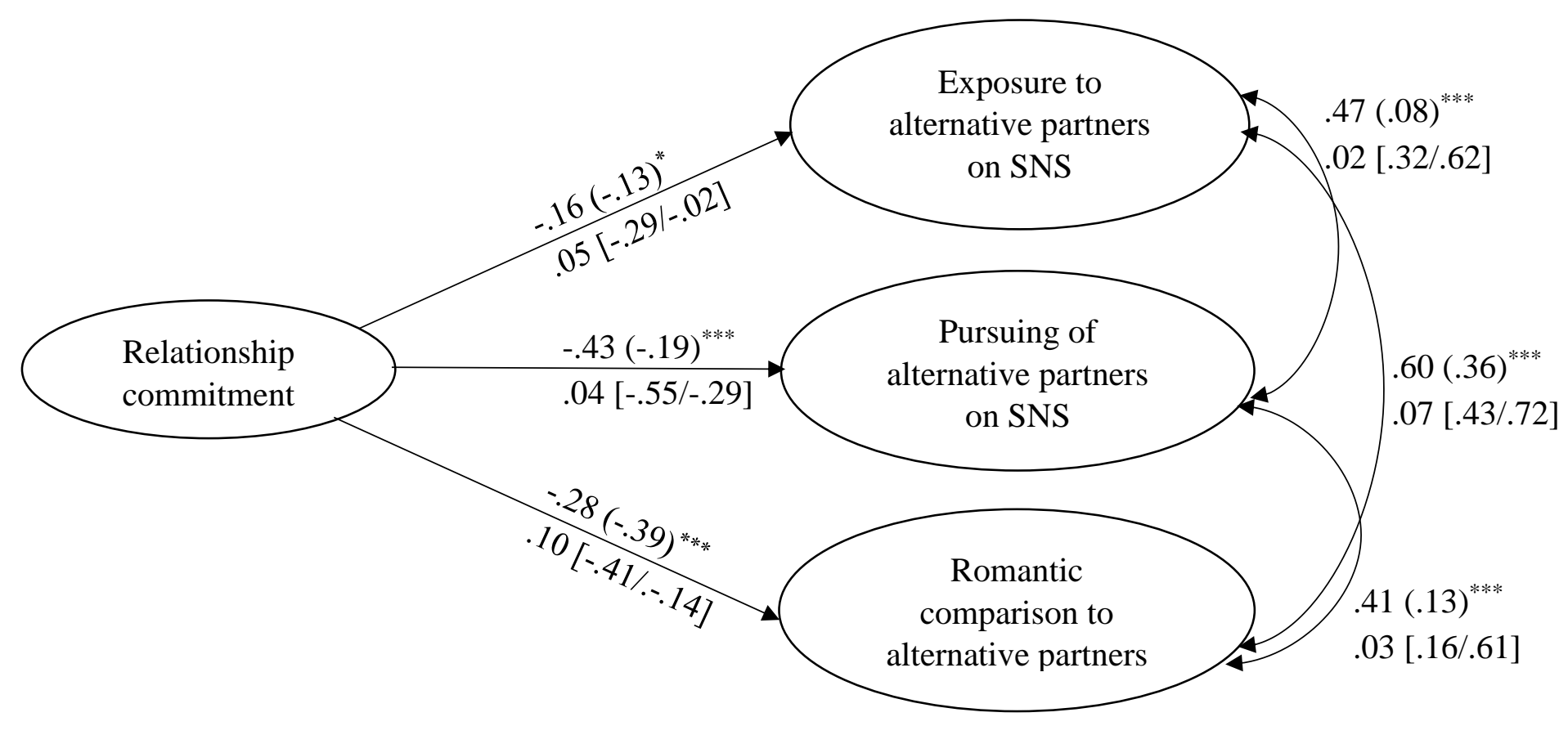

Figure 3. Structural equation model of alternative model 2.

$\chi^{2}(101)=284.29, p<.001, R M S E A=.07(90 \%$ CI: $.06 / .07), C F I=.94, T L I=.92, S R M R=.04, A I C=16852.57$.

Note. These results are controlled for age, gender, and SNS frequency.

Above the arrow: First value reflect standardized coefficient (beta), value within brackets reflects unstandardized coefficients (b-value).

Below the arrow: First value reflects standard errors, values within squared brackets reflect $95 \%$ confidence intervals.

$* p<.05, * * p<.01, * * * p<.001$ 
SOCIAL MEDIA USE AND ROMANTIC COMMITMENT 